\title{
Effect of within-species plant genotype mixing on habitat preference of a polyphagous insect predator
}

\author{
Velemir Ninkovic $\cdot$ Sate Al Abassi $\cdot$ \\ Elham Ahmed · Robert Glinwood · Jan Pettersson
}

Received: 7 May 2009/ Accepted: 26 October 2010/Published online: 16 November 2010

(C) The Author(s) 2010. This article is published with open access at Springerlink.com

\begin{abstract}
The effects of within-species plant genotype mixing on the habitat preference of a polyphagous ladybird were studied. Plant species diversity is often claimed to positively affect habitat preferences of insect predators, but the effects of within-species genotype diversity have not been extensively studied. In a field experiment with different barley (Hordeum vulgare) genotypes in mixed and pure stands, adult seven-spot ladybird Coccinella septempunctata, a polyphagous predator, preferred a specific combination of genotypes over the single genotypes alone before aphids had arrived in the crop, and again when aphids were emigrating. In laboratory experiments on adult ladybird orientation to odour from barley, ladybirds were attracted/arrested by the mixed odour of the same barley genotype mixture that was preferred in the field. Exposure of one barley genotype to volatiles from the other also caused the odour of the exposed plants to become more attractive to ladybirds. The results support the hypothesis that plant volatiles may attract or arrest foraging adult ladybirds, contributing to the selection of favourable habitats, and they show that within-species plant genotype mixing can shape interactions within multitrophic communities.
\end{abstract}

Keywords Plant-plant interactions · Barley · Aphids · Ladybirds · Plant volatiles

Communicated by Wolfgang Weisser.

V. Ninkovic ( $\square)$. S. Al Abassi · E. Ahmed · R. Glinwood .

J. Pettersson

Department of Ecology, Swedish University of Agricultural

Sciences, 75007 Uppsala, Sweden

e-mail: velemir.ninkovic@ekol.slu.se

\section{Introduction}

An emerging idea in ecology is that the function and stability of multitrophic communities in natural ecosystems are directly affected by plant biodiversity (Hooper et al. 2005). Plant species diversity can have strong effects on the abundances and distributions of other organisms, with increases in the number of plant species promoting a higher diversity of individual herbivorous and predatory arthropod species (Siemann et al. 1998; Haddad et al. 2001). Theories suggest that a complex plant species habitat promotes diversity of insect prey and predator populations (Root 1973; Bach 1980; Russell 1989), specifically predicting a reduced abundance of pest herbivores and increased richness and abundance of their natural enemies (Root 1973). The positive effects of plant species diversity have been shown in experiments in agricultural (Andow 1991) and natural ecosystems (e.g. Koricheva et al. 2000; Haddad et al. 2001; Otway et al. 2005), but knowledge of the mechanisms is still limited.

The significance of within-species plant genotype diversity for trophic interactions is even less well understood. Plant traits that have been shown to be specific for attracting or deterring predators are relatively fewer than those affecting herbivores, and it is assumed that variation between genotypes of one species has a weak effect at the third trophic level (Vinson 1999; Johnson and Agrawal 2005). However, Johnson (2008) found that plant genotypes can have a direct impact at the third tropic level, affecting the abundance and richness of predators in a natural system. Against the relatively homogeneous genetic background typical of most agricultural monocultures, genetic diversity within a plant species may play a greater role in trophic interactions. In fact, there is increasing evidence that mixing different genotypes of the same 
species of crop plant can affect organisms that use the plants as hosts (Power 1991; Mundt 2002; Ninkovic et al. 2002; Cadet et al. 2007).

Coexisting plants can interact via chemicals (allelopathy; cf. Rice 1984), and interactions of this type have been included in theories that seek to explain the effects of mixed cropping on herbivores and natural enemies (e.g. Uvah and Coaker 1984). However, the effects of chemical interactions between undamaged plants on trophic interactions have not been widely studied. It is now established that chemicals released by herbivore- or pathogen-damaged plants can induce responses in neighbouring plants that affect interactions with insect herbivores and their natural enemies (Dicke et al. 2003; Baldwin et al. 2006). However, it has also been shown that chemical interactions between unattacked plant individuals can affect organisms at higher trophic levels (Ninkovic et al. 2006). For example, volatile interactions between undamaged barley plants of different genotypes made them less acceptable to aphids (Kellner et al. 2010; Ninkovic et al. 2002, 2009; Glinwood et al. 2007, 2009), and volatile interactions between weeds and barley affected olfactory orientation by the polyphagous seven-spot ladybird Coccinella septempunctata L. (Ninkovic and Pettersson 2003). Studies on trophic processes have generally focused on plant-prey and preypredator interactions, while direct interactions between plants and predators of herbivores have been less studied. Due to the important role of olfactory cues in the foraging behaviours of many herbivore natural enemies, chemical mechanisms provide a route for direct interaction between the first and third trophic levels (e.g. Dicke et al. 2003).

Studies of polyphagous ladybirds can aid our understanding of the effects of plant genetic diversity at higher trophic levels. Several studies suggest that ladybirds respond positively to increased botanical diversity (Sengonca et al. 2002; Elliott et al. 2002), their general biology is well understood (Sloggett 2008) and they are known to utilise chemical information when foraging (Pettersson et al. 2008). In the current study, we examined the effect of genotype mixing within a single plant species on plant-arthropod interactions using the polyphagous C. septempunctata as a model. C. septempunctata is an aphid specialist, but its diet is considerably broader. It has been suggested that ecological flexibility is a key trait in the ecological success of the species, and it has been found to respond to several volatile chemical cues involved in foraging and habitat choice (Honek and Martinkova 2008; Pettersson et al. 2008). Barley, Hordeum vulgare L., grown in monoculture, provided a background with low genetic diversity that we manipulated by mixing genotypes (cultivars) in this study. We observed ladybird populations in plots of mixed barley genotypes in the field and then focussed on the olfactory behaviour of the insect as a mechanism that potentially contributes to habitat preference. The hypothesis was that mixing genotypes of a single plant species can affect habitat preference in this polyphagous predator.

\section{Materials and methods}

\section{Model system}

The study system consisted of several cultivars of spring barley, bird cherry-oat aphid Rhopalosiphum padi (L.) and seven-spot ladybird $C$. septempunctata. Both insects spend the winter in specific hibernating sites, $R$. padi as eggs on Prunus padus L. and C. septempunctata as hibernating adults in sites located at prominent locations in the landscape, such as ridges, rocks, water towers, etc. (Wiktelius et al. 1990; Majerus 1994; Hodek and Honek 1996). In Scandinavia, aphids and ladybirds usually arrive in barley fields in late May to early June. The barley crop matures during the beginning of July and, after an average of 2.5 generations, aphids leave the crop due to decreasing host plant quality (Wiktelius et al. 1990). The timing of aphid and ladybird arrival in the field depends on prevailing weather conditions. Low temperatures and low population density delay aphid migration (Wiktelius et al. 1990), meaning that ladybirds arrive earlier than aphids in the crop. Under these conditions, three separate phases of ladybird mobility can be recognised. The first is before aphid immigration to the crop, the second is after aphid immigration when aphids provide food and potentially modify plant volatile emissions (Pettersson et al. 2005) and the third is when the aphids emigrate from the crop. In the current study we took advantage of an uncommon situation with late and low aphid incidence but large overwintering ladybird populations.

Insects and plant material for laboratory experiments

A laboratory culture of $C$. septempunctata was established with adults collected at a hibernating site during the previous winter and kept in cages where reproduction took place. Barley (cv. Golf) infested with the cereal aphids R. padi and Sitobion avenae (F.), and flowering Brassica napus L. plants were the food sources. The culture was kept in a controlled environment chamber at $18-22^{\circ} \mathrm{C}$, 16:8 h L:D, and $80 \%$ relative humidity. Multiclonal cultures of $R$. padi were reared on barley (cv. Golf) in a glasshouse under the same conditions as $C$. septempunctata. For laboratory studies, plants of four barley cultivars (Kara, Alva, Frida and Hulda) were grown at $20 \pm 2{ }^{\circ} \mathrm{C}$ with a minimum of $16 \mathrm{~h}$ light (natural light supplemented by light from HQIE lamps). 
Field experiment

The field experiment was sown with spring barley on 5 May 2000. The genotypes Kara, Frida, Alva and Hulda were selected because they had been used in previous studies on the effects of mixed genotype cropping (Wiik 1987; Brown and Jørgensen 1991) and plant chemical interactions on aphids (Pettersson et al. 1999; Ninkovic et al. 2002). The pedigree of genotypes used in the field experiment is shown in Table 1 . The design was based on Ninkovic et al. (2002) with some modifications. Two types of field plot were established; binary mixtures of two genotypes and pure stands of single genotypes. Seeds of two genotypes were mixed before sowing, preventing the identification of single genotypes in the mixture by the observer. The ten treatments-four single genotypes and all six genotype mixtures-were laid out in a randomised complete block design with three replicates, and a plot size of $3.5 \times 7 \mathrm{~m}$. Gaps between plots were $1 \mathrm{~m}$, and the gaps were kept free from plants by hand weeding when necessary. No additional fertiliser was applied.

Estimates of $C$. septempunctata occurrence were made simultaneously by two observers on each half of the plot over a period of 3 min when the crop was at the 2-3 leaf stage, and $4 \mathrm{~min}$ at later stages. This avoided recording the same ladybird individual twice. Estimates were made on days with favourable weather conditions (mild, with low wind speed and moderately clear sky) in the middle of the day (11.00-14.00 h) to correspond with the active searching period of adults.

Aphid populations in the plots were sampled between 6 June 2000 and 7 July 2000, encompassing immigration and the main period of population development in springsown cereal crops for $R$. padi, the major aphid in the crop (Wiktelius et al. 1990). Aphids were recorded twice a week by counting on all plants in a $1 \mathrm{~m}$ long section of a crop row at three randomly chosen sites within each plot (Ninkovic et al. 2003). $R$. padi spring migration was estimated by

Table 1 Pedigree information for barley genotypes (cultivars) used in the experiments

\begin{tabular}{|c|c|}
\hline $\begin{array}{l}\text { Barley } \\
\text { genotype }\end{array}$ & Pedigree \\
\hline $\mathrm{Kara}^{\mathrm{a}}$ & $\left(\right.$ lngridM9 $\times$ Ansgar $\left.^{2}\right) \times$ Tellus $^{2} / \times \mathrm{WW} 6484^{2}$ \\
\hline Hulda ${ }^{b}$ & $\begin{array}{l}\left(\left(\left(\text { Ingrid M9 } \times \text { Ansgar }^{2}\right) \times \text { Tellus }^{2}\right) \times \text { WW6484 }^{2}\right) \times \\
\left((\text { Cilla M1M4 } \times \text { Lauda }) \times \text { Varunda }^{2}\right) \times 648\end{array}$ \\
\hline Frida $^{a}$ & Cilla $\times$ Aramir \\
\hline Alva $^{\mathrm{b}}$ & $/$ Balder $\times($ Seger $\times$ Binder $) / \times$ Vada \\
\hline
\end{tabular}

Kara and Hulda share a similar background, whereas the other cultivars do not

a Brown and Jørgensen (1991)

${ }^{\mathrm{b}}$ http://www.nordgen.org/index.php/en/content/view/full/344 collecting winged aphids from a $12 \mathrm{~m}$ high suction trap (Macaulay et al. 1988) located at Ultuna $\left(59^{\circ} 82^{\prime} \mathrm{N}\right.$, $\left.17^{\circ} 66^{\prime} \mathrm{E}\right), 200 \mathrm{~m}$ from the experimental field.

Statistical analysis of the field experiment

The Freeman-Tukey variance-stabilizing transformation $y=N^{1 / 2}+(N+1)^{1 / 2}$ was used for analyses of total ladybird and aphid counts $N$ (Freeman and Tukey 1950). The analyses were made in SAS 9.1 (SAS Institute 2004) with the MIXED procedure for fitting linear models with fixed and random effects.

Firstly, a model including all time points was fitted to the transformed counts of $C$. septempunctata and aphids, respectively. The fixed part of the model was

$y=\mu+\alpha_{i}+\beta_{i j}+\tau_{k}+(\alpha \tau)_{i k}+(\beta \tau)_{i j k}$

where $\mu$ is an intercept, $\alpha_{i}$ is the effect of the pure stand $(i=1)$ or the mixed stand $(i=2), \beta_{i j}$ is the effect of treatment $j$ nested within $i, \tau_{k}$ is the effect of time point $k$, and $(\alpha \tau)_{i k}$ and $(\beta \tau)_{i j k}$ are interaction effects. The model also included blocks and interactions between blocks and time points as independent, normally distributed random effects with an expected value of 0 . Possible covariance structures (spatial power, autoregressive (1), plots as a random effect) were assessed by Akaike's information criterion, a standard method for comparing different covariance structures (Fitzmaurice et al. 2004). The hypothesis of no interaction between stand type (pure or mixed) and time point and the hypothesis of no interaction between treatment and time point were investigated by $F$-tests calculated on sequential sums of squares. The degrees of freedom for the $F$-tests were calculated using the containment method in SAS (SAS, 2004). To analyse C. septempunctata occurrence, a model was fitted that also included the transformed counts of aphids as a continuous explanatory variable. In addition, the maximal values of C. septempunctata and aphids were calculated per plot, and Pearson's correlation coefficient was tested.

Secondly, for each time point, a model was fitted with treatment as a fixed factor and block and the error term as independent, normally distributed random effects. In these analyses, the hypothesis of no difference between the average effect of the pure-stand treatments and the average effect of the mixed-stand treatments was tested. Each mixed-stand treatment was compared to the average numbers of ladybirds in the pure stands of the corresponding genotypes.

Exposure of plants to plant volatiles in laboratory experiments

Plants of one barley genotype were exposed to volatiles from another in a series of two-chamber cages consisting of 
connected inducing and responding chambers (each chamber was $10 \times 10 \times 40 \mathrm{~cm}$ ) (Pettersson et al. 1999; Ninkovic et al. 2002) connected to a vacuum pump. Airflow through the system was $1.3 \mathrm{l} / \mathrm{min}$. Air passed over a pot containing ten plants of one barley genotype in the inducing chamber and then over a pot with ten barley plants of the second genotype in the responding chamber before being vented outside the greenhouse. To prevent plant interaction via root exudates, each pot was placed in a Petri dish and watered using an automated drop system (DGT Volmatic). Plants for experiments were grown in a separate glasshouse compartment under the same light and temperature conditions as in the cage compartment, which was a minimum $16 \mathrm{~h}$ of light at $18-22^{\circ} \mathrm{C}$. Natural light was supplemented by light from HQIE lamps. To minimize volatile interactions between genotypes during the preexposure period, pots with different genotypes were placed at least $1 \mathrm{~m}$ apart. A treatment time of five days was used, based on previous studies of volatile interaction between plants (Pettersson et al. 1999; Ninkovic et al. 2002). Plants were at the three-leaf stage when tested in the olfactometer.

\section{Olfactometry}

The results of the field experiments indicated a selective ladybird response to genotype mixtures, and subsequent olfactometer experiments were designed to test whether olfactory orientation may contribute to the pattern observed in the field. The combination Alva-Hulda was chosen to represent combinations that had given significant effects on ladybird occurrence in the field, and Alva-Kara was chosen to represent those that had not. Responses of adult C. septempunctata to odours of barley genotypes, genotype mixtures, and barley genotypes that had been exposed previously to volatiles from another genotype were tested using a two-arm olfactometer with a central neutral zone (Al Abassi et al. 1998; Ninkovic et al. 2001; Ninkovic and Pettersson 2003). Airflow in the olfactometer was $180 \mathrm{ml} / \mathrm{min}$, as measured with a flowmeter at the arm inlets.

Plants to be used as odour sources were held within a two-chamber cage, as described above. Cages containing the plants were directly connected to the olfactometer arms. Four different treatment arrangements were tested : (a) a two-chamber cage with one genotype in an inducing chamber and another in a responding chamber (volatile exposure between genotypes) was tested against plants of either genotype with the inducing chamber empty (no volatile exposure), (b) a two-chamber cage with one genotype in an inducing chamber and another in a responding chamber (volatile exposure between genotypes) was tested against a two-chamber cage with plants of the same genotype in an inducing chamber and a responding chamber (volatile exposure within genotype), with the same total number of plants in both odour sources, (c) a two-chamber cage with one genotype in a responding chamber that had been previously exposed for 5 days to another genotype in an inducing chamber (volatile exposure between genotypes, inducing chamber plant removed before test) was tested against plants of either genotype with the inducing chamber empty (no volatile exposure), and (d) a two-chamber cage with one genotype in a responding chamber that had been previously exposed for 5 days to another genotype in an inducing chamber (volatile exposure between genotypes, inducing chamber plant removed before test) was tested against a two-chamber cage with one genotype in a responding chamber that had been previously exposed for 5 days to the same genotype in the inducing chamber (volatile exposure within genotype, inducing chamber plant removed before test).

Test insects were randomly chosen from the culture. One adult ladybird was placed in the olfactometer and, after an adaptation period of $10 \mathrm{~min}$, the insect's position in the arena was registered at 2 min intervals, which was long enough to permit an adult ladybird to move from one end of the arena to the other (Ninkovic et al. 2001). The position of treatments in two-arm olfactometers was switched between the left and right arms in each separate olfactometer to account for any positional bias. Ten observations were made and the accumulated number of visits in the arm zones (excluding the central neutral zone) was regarded as one replicate. The test was terminated if a ladybird did not move at all between two consecutive observations and these individuals were not included in the analysis. Each individual was used only once. Wilcoxon matched pairs tests were used to analyse data.

A four-arm olfactometer was used to test the preference of $C$. septempunctata for odours from single genotypes. Four two-chamber cages were directly connected to the olfactometer, three containing a pot with ten plants of a single genotype (Kara, Hulda or Alva) and one empty cage. Replicates were performed simultaneously with five separate olfactometers connected to separate plant sources, and with one adult ladybird in each olfactometer. Precautions were taken to account for positional bias in the placement of odour stimulus arms. The positions of treatments in fourarm olfactometers were sequentially rotated through $90^{\circ}$ in each separate olfactometer to account for any positional bias. Olfactometers were cleaned between experiments, and 21 ladybirds were tested. The experiment was otherwise carried out as described above, and data were analysed using the Friedman ANOVA rank test.

Responses of wingless $R$. padi to odours of barley genotypes, genotype mixtures, and to odours from barley genotypes that had been previously exposed to volatiles from another genotype were tested using a four-arm olfactometer (Glinwood et al. 2003) with an airflow of 
$180 \mathrm{ml} / \mathrm{min}$. Plants used as odour sources were connected to the olfactometer in the same way as for olfactometry with ladybirds, as described above. All possible genotype combinations of four genotypes were tested in the study. A single aphid was introduced into an olfactometer and observations were made in the same way as for ladybirds, except that the insect's position was recorded every $3 \mathrm{~min}$ over a 30-min period (ten observations forming one replicate). Twenty aphids were tested with each combination. A four-arm olfactometer was used to test the odour preference of $R$. padi for odours from single genotypes. Four two-chamber cages were directly connected to the olfactometer containing a pot with ten plants of a single genotype (Kara, Hulda, Frida or Alva). Data were analysed using the Friedman ANOVA rank test and, where a significant difference was found, multiple comparisons between treatments were performed using the WilcoxonNemenyi-McDonald-Thompson test (Hollander and Wolfe 1999) in the software package R (http://www. R-project.org).

\section{Results}

Ladybird and aphid populations in the field

Development of the ladybird population was characterised by three phases in relation to the presence of aphids: an initial immigration phase before aphids had arrived in the crop, an intermediate phase coinciding with aphid infestation and population increase, and a final emigration phase when the aphid population was diminishing.

According to Akaike's information criterion, the repeated measurements were best fitted by modelling plots as a random effect. In this analysis, the variance between plots was estimated to be 0 . The interaction between stand type (pure or mixed) and time point was significant $\left(F_{9,612}=2.61\right.$, $P=0.008)$.

During the initial phase, peak $C$. septempunctata abundance was significantly higher in the Alva-Hulda mixture compared to pure plots (Fig. 1), whereas this effect was not observed for any of the other five two-genotype mixtures tested (data not shown). The initial peak corresponds to ladybird immigration to the barley crop before aphids have arrived (Fig. 2) (as also illustrated by the suction trap data in Fig. 3). On 6 June 2000, during the initial immigration phase, the Hulda-Alva genotype mixture had a significantly higher number of ladybirds than pure plots of Hulda $(P=0.003)$ or Alva $(P=0.012)$.

Suction trap catches (Fig. 3) showed that aphid immigration into the crop started on 13 June 2000 and reached a peak around the end of June/start of July, the intermediate phase. Significantly higher numbers of ladybirds were

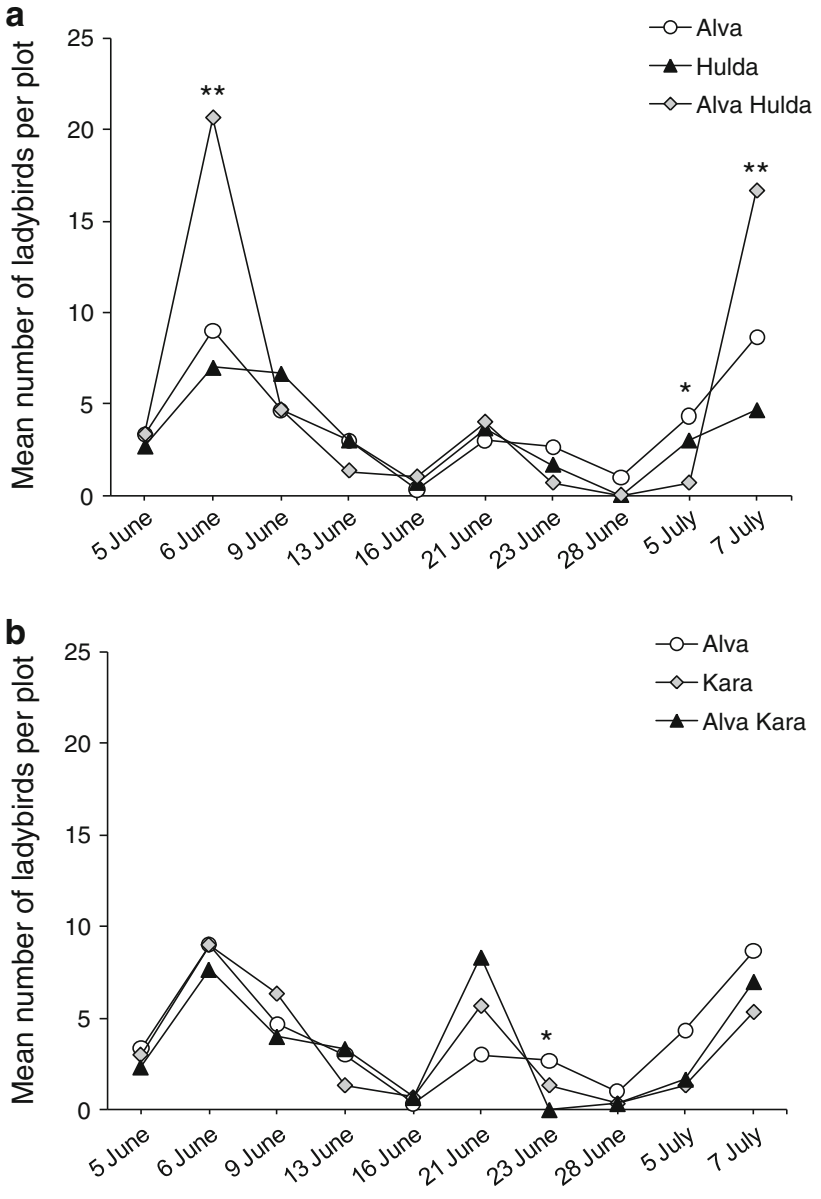

Fig. 1 Occurrence of the ladybird C. septempunctata in plots with mixtures of barley genotypes and genotypes grown in pure stands at time points during the crop season. Figures show mean numbers of ladybirds per plot in binary mixtures of genotypes compared with both single genotypes. $* P<0.05$, $* * P<0.01$, LSD pair-wise comparisons

found in pure stands than in genotype mixtures at two time points during this phase, on 23 June and 5 July 2000 $(P=0.005$ and $P=0.01)$. On 23 June 2000, plots with Alva had higher numbers of ladybirds than the Alva-Frida $(P=0.04)$ or Alva-Kara $(P=0.01)$ mixtures, whereas there were no significant differences between Frida or Kara compared with their respective mixture. On 5 July 2000, significantly higher numbers of ladybirds were observed in plots with Alva $(P=0.02)$ than in the Hulda-Alva mixture, but not in plots with Hulda (Fig. 1).

Crop maturation and a rapid decline in aphid numbers typified the final ladybird emigration phase. On 7 July 2000 , when the aphids were leaving the barley field, the pattern of ladybird occurrence in the Alva-Hulda mixture compared with the pure stands was similar to that observed during the initial immigration phase. A significantly higher number of ladybirds was observed in Hulda-Alva than in plots with Hulda $(P=0.004)$ or Alva $(P=0.04)$ alone (Fig. 1$)$. 

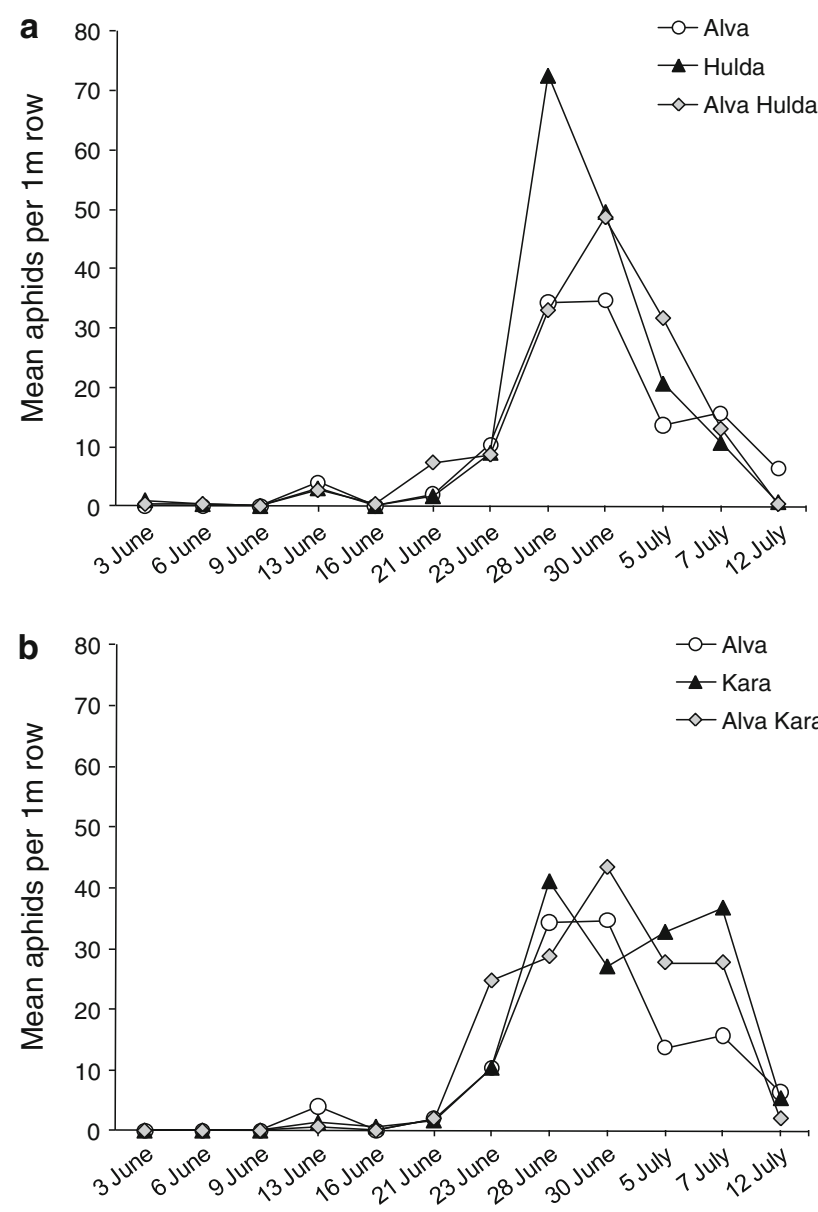

Fig. 2 Occurrence of cereal aphids in plots with mixtures of barley genotypes and genotypes grown in pure stands at time points during the crop season. Figures show mean numbers of aphids per $1 \mathrm{~m}$ crop row in binary mixtures of genotypes compared with both single genotypes. $* P<0.05$, $* * P<0.01$, LSD pair-wise comparisons

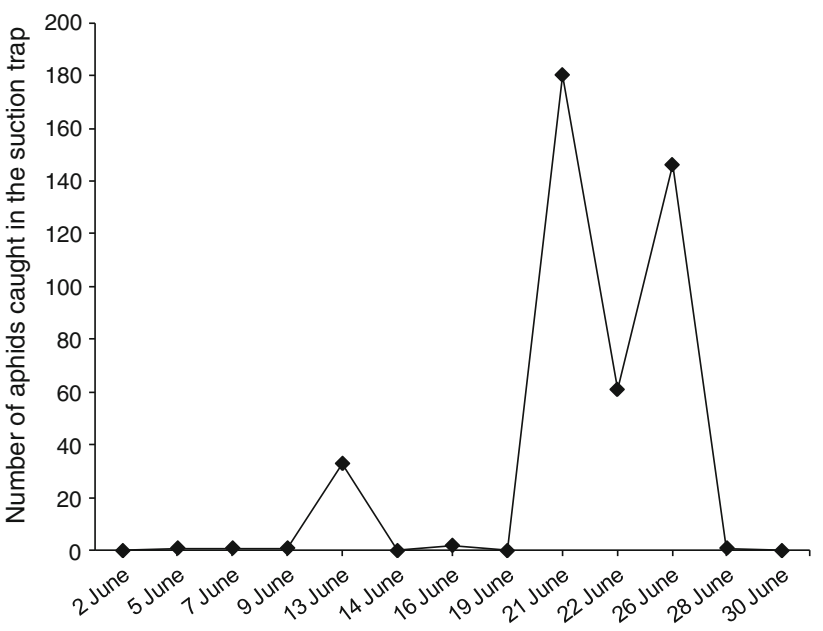

Fig. 3 Aphid migrants collected from a suction trap located $200 \mathrm{~m}$ from the field plots during the experiment
For aphid populations, the repeated measurements were best fitted by modelling plots as a random effect according to Akaike's information criterion. No significant difference between the numbers of aphids in pure and mixed stands was found $\left(F_{1,198}=0.76, P=0.384\right)$. The variance between plots was estimated, on the transformed scale, as 0.048 . There were no significant interactions between treatments and time point $\left(F_{88,198}=1.31, P=0.06\right)$ or between type of stand (pure or mixed) and time point $\left(F_{11,198}=1.76\right.$, $P=0.064)$. Significant effects were observed for treatments within type of stand (pure or mixed) $\left(F_{8,198}=2.70\right.$, $P=0.008$ ) and for time points (indicating changes in aphid population development $\left(F_{11,22}=40.34, \quad P<0.001\right)$. The interaction between treatments within stand types (mixed and pure stands) and time point was not significant $\left(F_{72,162}=1.07, P=0.352\right)$. Aphid incidence was lower than average in the region during the field season (Bommarco et al. 2007). The presence of aphids did not significantly explain differences between plots in the number of ladybirds $\left(F_{1,143}=2.30, P=0.131\right)$. The correlation between maximal values of ladybirds and aphids was estimated at $0.028\left(t_{28}=0.15, P=0.882\right)$. This indicates that cues other than aphid presence contributed to the distribution of ladybirds in the field.

\section{Olfactometry}

A significantly greater arresting/attracting effect on ladybird walking behaviour was apparent in the odour of Alva-Hulda compared with the odour of Hulda or Alva alone (Table 2a). The ladybird preference was apparent, even when equal amounts of plant biomass were presented as odour sources (e.g., Alva and Hulda vs. Alva and Alva) (Table 2b).

The odour of Hulda previously exposed to volatiles from Alva had a significant arresting/attracting effect on C. septempunctata compared with the odour of unexposed Hulda (Table 2c), but not when compared with Hulda previously exposed to volatiles from Hulda (Table 2d). The odour of Alva previously exposed to volatiles from Hulda had no significant arresting/attracting effect on $C$. septempunctata when compared with the odour of unexposed Alva (Table 2c) or with Alva that had previously been exposed to volatiles from Alva (Table 2d).

In the equivalent tests with Alva and Kara, no significant effect on ladybird behaviour was found in any combination (Table 2a-d). Ladybirds showed no preference for the odours of genotypes Alva, Kara or Hulda (Friedman ANOVA $F=2.61, d f=3, P=0.45)$, so the effects of mixed genotypes are not likely to be due to a greater attractiveness of any of the genotypes per se.

Aphids showed no preference for the odours of genotypes Alva, Kara, Hulda or Frida (Friedman ANOVA 
Table 2 C. septempunctata olfactory response to odour of barley after the exposure of one genotype to volatiles from another

\begin{tabular}{|c|c|c|c|c|c|}
\hline Inducing genotype & Responding genotype & \multicolumn{2}{|c|}{ Olfactometer arm (mean \pm SE) } & $n$ & $P$ level \\
\hline \multicolumn{6}{|c|}{ (a) Inducing genotype remained in the inducing chamber } \\
\hline A & $\mathrm{B}$ & $\mathrm{AB}$ & 0B & & \\
\hline Alva & Hulda & $4.8 \pm 0.26$ & $3.2 \pm 0.31$ & 19 & 0.019 \\
\hline Hulda & Alva & $4.9 \pm 0.31$ & $3.6 \pm 0.28$ & 21 & 0.033 \\
\hline Alva & Kara & $5.1 \pm 0.50$ & $3.4 \pm 0.39$ & 18 & 0.088 \\
\hline Kara & Alva & $4.6 \pm 0.37$ & $3.8 \pm 0.32$ & 20 & 0.247 \\
\hline \multicolumn{6}{|c|}{ (b) Inducing genotype remained in the inducing chamber } \\
\hline A & $\mathrm{B}$ & $\mathrm{AB}$ & BB & & \\
\hline Alva & Hulda & $5.2 \pm 0.36$ & $3.6 \pm 0.27$ & 19 & 0.011 \\
\hline Hulda & Alva & $4.7 \pm 0.27$ & $3.6 \pm 0.22$ & 20 & 0.033 \\
\hline Alva & Kara & $4.3 \pm 0.42$ & $4.3 \pm 0.35$ & 15 & 0.950 \\
\hline Kara & Alva & $4.2 \pm 0.42$ & $4.7 \pm 0.37$ & 21 & 0.444 \\
\hline \multicolumn{6}{|c|}{ (c) Inducing genotype was removed from the inducing chamber } \\
\hline A & B & $\mathrm{A}^{*} \mathrm{~B}$ & OB & & \\
\hline Alva & Hulda & $4.8 \pm 0.34$ & $3.0 \pm 0.29$ & 23 & 0.009 \\
\hline Hulda & Alva & $4.5 \pm 0.50$ & $3.5 \pm 0.35$ & 17 & 0.297 \\
\hline Alva & Kara & $4.0 \pm 0.43$ & $3.7 \pm 0.42$ & 15 & 0.826 \\
\hline Kara & Alva & $4.7 \pm 0.40$ & $3.6 \pm 0.36$ & 19 & 0.111 \\
\hline \multicolumn{6}{|c|}{ (d) Inducing genotype was removed from the inducing chamber } \\
\hline A & B & $\mathrm{A} * \mathrm{~B}$ & $\mathrm{~B} * \mathrm{~B}$ & & \\
\hline Alva & Hulda & $3.8 \pm 0.36$ & $4.3 \pm 0.41$ & 17 & 0.379 \\
\hline Hulda & Alva & $4.6 \pm 0.35$ & $3.7 \pm 0.33$ & 20 & 0.199 \\
\hline Alva & Kara & $4.0 \pm 0.30$ & $3.0 \pm 0.22$ & 21 & 0.058 \\
\hline Kara & Alva & $4.6 \pm 0.30$ & $3.8 \pm 0.40$ & 17 & 0.280 \\
\hline
\end{tabular}

$A B$ represents a two-chamber cage where a responding genotype $\mathrm{B}$ was exposed to volatiles from an inducing genotype A. $O B$ is two-chamber cage without plants in the first chamber, where genotype B was not exposed to plant volatiles. $B B$ is two-chamber cage with the same genotype in both chambers, where genotype $\mathrm{B}$ is exposed to volatiles from the same genotype. $A * B$ is a two-chamber cage with different genotypes in each chamber, where the inducing genotype A was removed. $B * B$ is two-chamber cage with the same genotype in both chambers, where cultivar $\mathrm{B}$ was removed from the inducing chamber. Blank is a two-chamber cage without any plants

$P$ values from a Wilcoxon matched pairs test, $n$ number of individual $C$. septempunctata tested against each combination

$F=1.77, d f=3, P=0.62$ ). The odour of Alva-Kara was not significantly less attractive than that of an equal amount of Kara alone $(P=0.06)$ or an odour from unexposed Kara $(P=0.98)$, or air from a two-chamber cage without plants $(P=0.92)$ (Table 3a). However, the odour of Kara that had been previously exposed to volatiles from Alva was significantly less attractive than the odour of Kara previously exposed to volatiles from Kara $(P=0.026)$, but not than unexposed Kara $(P=0.86)$ (Table $3 b)$. No significant effects on aphid olfactory behaviour were observed in any other tested combination of the four genotypes (data not shown).

\section{Discussion}

The aim of the study was to test the hypothesis that mixing genotypes of a single plant species can affect habitat preference in C. septempunctata. The results of the field experiments indicate that $C$. septempunctata responds to a specific plant genotype mixture during the immigration phase when its preferred food, aphids, is absent. Results of laboratory experiments support this, suggesting that volatile stimuli from the barley genotype combination AlvaHulda may attract or arrest foraging C. septempunctata. The arrival of aphids in the crop may disrupt or override this response, since aphid-related cues are known to influence ladybird searching behaviour (Pettersson et al. 2005), and no significant effects of genotype mixing on ladybird occurrence were found during this phase.

When aphids left the crop, there were once again higher peak numbers in mixed Alva-Hulda plots than in plots of either genotype alone. Aphids are a vital food source for C. septempunctata, and the ladybird can use volatile cues from aphid-infested plants (Ninkovic et al. 2001). Like all foraging insects, ladybirds should preferentially respond to cues giving the highest informational value on the availability and quality of food. Thus it can be hypothesized 
Table $3 R$. padi olfactory response to odour of barley after the exposure of one cultivar to volatiles from another

\begin{tabular}{|c|c|c|c|c|c|c|}
\hline Inducing genotype & Responding genotype & \multicolumn{4}{|c|}{ Observations in olfactometer arm (mean $\pm \mathrm{SE}$ ) } & $P$ - level \\
\hline \multicolumn{7}{|c|}{ (a) Inducing genotype remained in the inducing chamber } \\
\hline A & $\mathrm{B}$ & $\mathrm{AB}$ & OB & BB & Blank & \\
\hline Alva & Hulda & $2.0 \pm 0.37$ & $2.5 \pm 0.41$ & $2.4 \pm 0.39$ & $2.1 \pm 0.31$ & n.s. \\
\hline Hulda & Alva & $1.3 \pm 0.23$ & $2.3 \pm 0.42$ & $2.4 \pm 0.46$ & $2.2 \pm 0.39$ & n.s. \\
\hline Alva & Kara & $1.6 \pm 0.32$ & $1.6 \pm 0.28$ & $3.3 \pm 0.42$ & $2.2 \pm 0.44$ & 0.027 \\
\hline Kara & Alva & $1.9 \pm 0.24$ & $2.7 \pm 0.36$ & $2.7 \pm 0.45$ & $1.9 \pm 0.35$ & n.s. \\
\hline \multicolumn{7}{|c|}{ (b) Inducing genotype was removed from the inducing chamber } \\
\hline A & $\mathrm{B}$ & $A * B$ & OB & $\mathrm{B} * \mathrm{~B}$ & Blank & \\
\hline Alva & Hulda & $2.5 \pm 0.37$ & $2.4 \pm 0.39$ & $1.8 \pm 0.47$ & $1.7 \pm 0.39$ & n.s. \\
\hline Hulda & Alva & $2.3 \pm 0.44$ & $1.9 \pm 0.35$ & $2.2 \pm 0.30$ & $2.0 \pm 0.37$ & n.s. \\
\hline Alva & Kara & $1.5 \pm 0.33$ & $1.9 \pm 0.34$ & $3.5 \pm 0.47$ & $1.8 \pm 0.32$ & 0.026 \\
\hline Kara & Alva & $1.9 \pm 0.31$ & $2.7 \pm 0.39$ & $2.7 \pm 0.40$ & $1.8 \pm 0.32$ & n.s. \\
\hline
\end{tabular}

$A B$ represents a two-chamber cage where a responding genotype $\mathrm{B}$ was exposed to volatiles from an inducing genotype A. $O B$ is two-chamber cage without plants in the first chamber, where genotype $\mathrm{B}$ was not exposed to plant volatiles. $B B$ is a two-chamber cage with the same genotype in both chambers, where genotype $\mathrm{B}$ is exposed to volatiles from the same genotype. $A * B$ is a two-chamber cage with different genotypes in each chamber, where the inducing genotype A was removed. $B * B$ is two-chamber cage with the same genotype in both chambers, where cultivar $\mathrm{B}$ was removed from the inducing chamber

$P$ values from the Friedman ANOVA test

n.s. not significant $P>0.05$

that, before aphids arrive, ladybirds respond to the best available cue, that denoting the specific genotype mixture, but after aphid populations have built up on plants, the resulting cues provided more reliable information on food availability and thus overruled responses to the genotype mixture. This hypothesis is supported by the laboratory study of Glinwood et al. (2009). They showed that after the exposure of one barley cultivar to volatiles of a different cultivar, C. septempunctata was more attracted to the odour of the exposed plants than to that of unexposed plants. However, when both exposed and unexposed plants were infested with the aphid $R$. padi, this preference was lost, suggesting that the response to odour cues associated with plant exposure was overruled by those denoting aphid infestations. However, there was no strong correlation between aphid and ladybird numbers in the plots. Thus, it can be hypothesized that a specific barley genotype mixture can positively affect ladybird searching in the absence of aphid prey, but this response is overruled by cues from aphids and aphid attacked plants.

In natural ecosystems, increased plant species diversity is predicted to favour polyphagous predators (Siemann et al. 1998; Haddad et al. 2001), while within-species genetic diversity has not been considered to have the same ecological importance (Vinson 1999; Johnson and Agrawal 2005). In agricultural systems, however, the dominance of monocropping provides a genetic homogeneous ecosystem. We hypothesised that, within such a system, even relatively small increases in the number of genotypes present, as attained by mixing plant genotypes, may trigger effects at higher trophic levels. The results partly support this hypothesis in that the mixing of certain plant genotypes affected ladybirds but did not affect aphids.

The foraging behaviour of C. septempunctata is influenced by habitat characteristics, including the identity and diversity of plants (Pettersson et al. 2005, 2008), and our results are in line with previous reports showing a positive response of polyphagous ladybirds to increased botanical diversity (Honek and Martinkova 1991; Leather et al. 1999; Elliott et al. 2002; Sengonca et al. 2002; Ninkovic and Pettersson 2003). Experimental evidence shows that adult ladybirds can use volatile plant chemical cues to discriminate between plant species (Kranz and Sengonca 2000, 2001; Schaller and Nentwig 2000; Timms et al. 2008) and assess the occurrence of insect prey or associated plant stress (Schmid 1992; Ninkovic et al. 2001; James 2003, 2005; Zhu and Park 2005; Girling and Hassall 2008). Ninkovic and Pettersson (2003) showed that volatile mixing and transfer between some common weeds and barley attracted ladybirds, and correlated with increased ladybird occurrence in weedy patches in barley fields.

Our results suggest that $C$. septempunctata can potentially discriminate between particular genotype mixtures and pure stands via olfactory cues. There are two basic mechanisms that may facilitate this. First, volatile transfer between plants of different genotypes might induce changes in the odour profiles of exposed plants. Second, if the volatile profiles of the genotypes are different, combining 
them may provide a more attractive blend than either genotype alone. These mechanisms need not be mutually exclusive, and appear to depend on specific combinations of genotypes. The findings are supported by results with further barley genotype combinations, where both volatile exposure and mixing in specific binary combinations resulted in increased olfactory attraction of ladybirds (Glinwood et al. 2009). In the current study, the barley genotype combination that affected ladybird orientation in the laboratory also affected habitat preference in the field, suggesting that odour cues may be among the behavioural mechanisms that serve to orient ladybirds to the mixed genotype stands.

If ladybirds can detect indicators of specific genotypic compositions of the plant habitat, their behavioural responses may be activated by relatively small increases in the number of genotypes in the context of the otherwise homogeneous backgrounds provided by most monocrop stands. Some investigations have not supported an effect of plant composition on ladybird habitat preference (Andow and Risch 1985; Gianoli et al. 2006). Because the effects of plant genotypic diversity on trophic interactions can be due to a combination of interactive and additive effects among genotypes within genetically diverse patches (Johnson 2008), the strength of the effect may be context-specific rather than a general phenomenon. This was the case in the current study, with effects occurring in a specific combination of barley genotypes in both field and laboratory.

This is the first study to show that mixing certain genotypes of a single plant species can affect the behavioural responses of a polyphagous predator. This appeared to be a direct interaction between the first and third trophic levels, with no observable impact at the second trophic level. An attempt to elucidate the possible behavioural mechanisms driving the observed effect suggests that olfactory cues may be involved, but the mechanisms behind the trophic effects of plant genetic diversity need to be more widely studied. Nevertheless, the current study contributes to a new perspective on the effects of plant genotype mixing on trophic interactions.

\begin{abstract}
Acknowledgments We thank Dr Johannes Forkman (Department of Crop Production Ecology, SLU) for valuable statistical support. This work was supported financially by the Swedish Research Council for the Environment, Agricultural Sciences and Spatial Planning (Formas), and the Swedish Foundation for Strategic Environmental Research (Mistra) through the PlantComMistra programme. NordGen Plants and Svalöf Weibull $\mathrm{AB}$ are thanked for supplying barley genotypes.
\end{abstract}

Open Access This article is distributed under the terms of the Creative Commons Attribution Noncommercial License which permits any noncommercial use, distribution, and reproduction in any medium, provided the original author(s) and source are credited.

\section{References}

Al Abassi S, Birkett MA, Pettersson J, Pickett JA, Wadhams LJ, Woocock CM (1998) Ladybird beetle odour identified and found to be responsible for attraction between adults. Cell Mol Life Sci 54:876-879

Andow DA (1991) Vegetational diversity and arthropod population responses. Annu Rev Entomol 36:561-586

Andow DA, Risch SJ (1985) Predation in diversified agroecosystems: relations between a coccinellid predator Coleomegilla maculate and its food. J Appl Ecol 22:357-372

Bach CE (1980) Effect of plant diversity and time of colonization on an herbivore-plant interaction. Oecologia 44:319-326

Baldwin IT, Halitschke R, Paschold A, von Dahl CC, Preston CA (2006) Volatile signaling in plant-plant interactions: talking trees in the genomics era. Science 311:812-815

Bommarco R, Wetterlind S, Sigvald R (2007) Cereal aphid populations in non-crop habitats show strong density dependence. J Appl Ecol 44:1013-1022

Brown JKM, Jørgensen HA (1991) A catalogue of mildew resistance genes in European barley varieties. In: Jørgensen JH (ed) Integrated control of cereal mildew: virulence patterns and their change. Rise National Laboratory, Roskilde, pp 263-286

Cadet P, Berry SD, Leslie GW, Spaull VW (2007) Management of nematodes and a stalk borer by increasing within-field sugarcane cultivar diversity. Plant Pathol 56:526-535

Dicke M, van Poecke RMP, de Boer JG (2003) Inducible indirect defence of plants: from mechanisms to ecological functions. Basic Appl Ecol 4:27-42

Elliott NC, Kieckhefer RW, Michels GJ, Giles KL (2002) Predator abundance in alfalfa fields in relation to aphids, within-field vegetation, and landscape matrix. Environ Entomol 31:253-260

Fitzmaurice GM, Laird NM, Ware JH (2004) Applied longitudinal analysis. Wiley, New Jersy

Freeman MF, Tukey JW (1950) Transformations related to the angular and the square root. Ann Math Stat 21:607-611

Gianoli E, Ramos I, Alfaro-Tapia A, Valdez Y, Echegaray ER, Yabar E (2006) Benefits of a maize-bean-weeds mixed cropping system in Urubamba Valley, Peruvian Andes. Int J Pest Manage 52:283-289

Girling RD, Hassall M (2008) Behavioural responses of the seven-spot ladybird Coccinella septempunctata to plant headspace chemicals collected from crop Brassicas and Arabidopsis thaliana infested with Myzus persicae. Agr For Entomol 10:297-306

Glinwood RT, Pettersson J, Ninkovic V, Ahmed E, Birkett M, Pickett JA (2003) Change in acceptability of barley plants to aphids after exposure to allelochemicals from couch-grass (Elytrigia repens). J Chem Ecol 29:259-272

Glinwood R, Gradin T, Karpinska B, Jonsson L, Ninkovic V (2007) Aphid acceptance of barley exposed to volatile phytochemicals differs between plants exposed in daylight and darkness. Plant Signal Behavior 2:321-326

Glinwood R, Ahmed E, Qvarfordt E, Ninkovic V, Pettersson J (2009) Airborne interactions between undamaged plants of different cultivars affect insect herbivores and natural enemies. Arthropod-Plant Interact 3:219-224

Haddad NM, Tilman D, Haarstad J, Ritchie M, Knops JMH (2001) Contrasting effects of plant richness and composition on insect communities: a field experiment. Am Nat 158:17-35

Hodek I, Honek A (1996) Ecology of Coccinellidae. Kluwer, Dordrecht

Hollander M, Wolfe DA (1999) Nonparametric statistical methods, 2nd edn. Wiley, New York

Honek A, Martinkova Z (1991) Competition between maize and barnyard grass Echinochloa crus-galli, and its effects on aphids and their predator. Acta Oecol 12:741-751 
Honek A, Martinkova Z (2008) Why is Coccinella septempunctata so successful (a point of view). Eur J Entomol 105:1-12

Hooper DU, Chapin FS III, Ewel JJ, Hector A, Inchausti P, Lavorel S, Lawton JH, Lodge DM, Loreau M, Naeem S, Schmid B, Setälä H, Symstad AJ, Vandermeer J, Wardle DA (2005) Effects of biodiversity on ecosystem functioning: a consensus of current knowledge. Ecol Monogr 75:3-35

James GD (2003) Field evaluation of herbivore-induced plant volatiles as attractants for beneficial insects: methyl salicylate and the green lacewing, Chrysopa nigricorni. J Chem Ecol 29:1601-1609

James GD (2005) Further field evaluation of synthetic herbivoreinduced plant volatiles as attractants for beneficial insects. J Chem Ecol 31:481-495

Johnson MTA (2008) Bottom-up effects of plant genotype on aphids, ants, and predators. Ecology 89:145-154

Johnson MTA, Agrawal AA (2005) Plant genotype and environment interact to shape a diverse arthropod community in evening primrose (Oenothera biennis). Ecology 86:875-885

Kellner M, Kolodinska Brantestam A, Åhman I, Ninkovic V (2010) Plant volatile induced aphid resistance in barley cultivars is related to cultivar age. Theor Appl Genet 121:1133-1139

Koricheva J, Mulder CPH, Schmid B, Joshi J, Huss-Danell K (2000) Numerical responses of different trophic groups of invertebrates to manipulations of plant diversity in grasslands. Oecologia 125:271-282

Kranz J, Sengonca C (2000) Olfactometric studies on the attractiveness of different plant species for beneficial arthropods. Mitt Dtsch Ges Allg Angew Ent 12:115-118

Kranz J, Sengonca C (2001) Attractiveness of selected plant species for Coccinella septempunctata L. (Col., Coccinellidae) in the field. Mitt Dtsch Ges Allg Angew Ent 13:189-192

Leather SR, Cooker RCA, Fellowes MDE, Rombe R (1999) Distribution and abundance of ladybirds (Coleoptera: Coccinellidae) in non-crop habitats. Eur J Entomol 96:23-27

Macaulay EDM, Tatchell GM, Taylor LR (1988) The Rothamsted insect survey "12-metre" suction trap. B Entomol Res 78:121129

Majerus MEN (1994) Ladybirds. Harper Collins, London

Mundt CC (2002) Use of multiline cultivars and cultivar mixtures for disease management. Annu Rev Phytopathol 40:381-410

Ninkovic V, Pettersson J (2003) Searching behaviour of the sevenspotted ladybird, Coccinella septempunctata-effects of plant-plant odour interaction. Oikos 100:65-70

Ninkovic V, Al Abbasi S, Pettersson J (2001) The influence of aphidinduced plant volatiles on ladybird beetle searching behaviour. Biol Control 21:191-195

Ninkovic V, Olsson U, Pettersson J (2002) Mixing barley cultivars affects aphid host plant acceptance in field experiments. Entomol Exp Appl 102:177-182

Ninkovic V, Ahmed E, Glinwood R, Pettersson J (2003) Effects of two types of semiochemical on population development of the bird cherry oat aphid Rhopalosiphum padi in a barley crop. Agric For Entomol 5:27-33

Ninkovic V, Glinwood R, Pettersson J (2006) Communication between undamaged plants by volatiles: the role of allelobiosis. In: Baluška F, Mancuso S, Volkmann D (eds) Communication in plants: neuronal aspects of plant life. Springer, Heidelberg, pp 421-434

Ninkovic V, Glinwood R, Dahlin I (2009) Weed-barley interactions affect plant acceptance by aphids in laboratory and field experiments. Entomol Exp Appl 133:38-45
Otway SJ, Hector A, Lawton JH (2005) Resource dilution effects on specialist insect herbivores in a grassland biodiversity experiment. J Anim Ecol 74:234-240

Pettersson J, Ninkovic V, Ahmed E (1999) Volatiles from different barley cultivars affect aphid acceptance of neighbouring plants. Acta Agr Scand B-S P 49:152-157

Pettersson J, Ninkovic V, Glinwood R, Birkett MA, Pickett JA (2005) Foraging in a complex environment-semiochemicals support searching behaviour of the seven spot ladybird. Eur J Entomol 102:365-370

Pettersson J, Ninkovic V, Glinwood R, Al Abassi S, Birkett M, Pickett J, Wadhams L (2008) Chemical stimuli supporting foraging behaviour of Coccinella septempunctata $\mathrm{L}$ (Coleoptera: Coccinellidae): volatiles and allelobiosis. Appl Entomol and Zool 43:315-321

Power AG (1991) Virus spread and vector dynamics in genetically diverse plant populations. Ecology 72:232-241

Rice EL (1984) Allelopathy, 2nd edn. Academic New York

Root RB (1973) Organization of plant-arthropod association in simple and diverse habitats: the fauna of collards (Brassica oleraceae). Ecol Monogr 43:95-124

Russell EP (1989) Enemies hypothesis: a review of the effects of vegetational diversity on predatory insects and parasitoids. Environ Entomol 18:590-599

SAS Institute Inc (2004) SAS/STAT ${ }^{\circledR} 9.1$ user's guide. SAS Institute Inc, Cary

Schaller M, Nentwig W (2000) Olfactory orientation of the sevenspot ladybird beetle, Coccinella septempunctata (Coleoptera: Coccinellidae): attraction of adults to plants and conspecific females. Eur J Entomol 97:155-159

Schmid A (1992) Investigations on the attractiveness of agricultural weeds to aphidophagous ladybirds (Coleoptera, Coccinellidae). Agrarökologie 5:122

Sengonca C, Kranz J, Blaeser P (2002) Attractiveness of three weed species to polyphagous predators and their influence on aphid populations in adjacent lettuce cultivations. J Pest Sci 75:161-165

Siemann E, Tilman D, Haarstad J, Ritchie M (1998) Experimental tests of the dependence of arthropod diversity on plant diversity. Am Nat 152:738-750

Sloggett JJ (2008) Weighty matters: body size, diet and specialization in aphidophagous ladybird beetles (Coleoptera : Coccinellidae). Eur J Entomol 105:381-389

Timms JE, Oliver TH, Straw NA, Leather SR (2008) The effects of host plant on the coccinellid functional response: is the conifer specialist Aphidecta obliterata (L.) (Coleoptera: Coccinellidae) better adapted to spruce than the generalist Adalia bipunctata (L.) (Coleoptera: Coccinellidae)? Biol Control 47:273-281

Uvah III, Coaker TH (1984) Effect of mixed cropping on some insect pests of carrots and onions. Entomol Exp Appl 36:159-167

Vinson SB (1999) Parasitoid manipulation as a plant defense strategy. Ann Entomol Soc Am 92:812-828

Wiik L (1987) Cultivars of spring barley and powdery mildew (Erysiphe graminis f. sp. hordei) in Sweden. In: Limpert E, Wolfe MS (eds) Integrated control of cereal mildews. Martinus Nijhoff, Dordrecht, pp 103-112

Wiktelius S, Weibull J, Pettersson J (1990) Aphid host plant ecology: the bird cherry-oat aphid as a model. In: Campbell RK, Eikenbary RD (eds) Aphid-plant genotype interactions. Elsevier, Amsterdam, pp 21-36

Zhu JW, Park KC (2005) Methyl salicylate, a soybean aphid-induced plant volatile attractive to the predator Coccinella septempunctata. J Chem Ecol 31:1733-1746 